\title{
Práticas jurídicas e sociais legitimadoras dos modelos econômicos liberal e neoliberal de apropriação
}

Legitimating juridical and social practices of the liberal economic model of appropriation

Bárbara Nascimento de Lima ${ }^{1}$ Ricardo Manoel de Oliveira Morais²

Resumo: Este artigo objetiva analisar as práticas jurídicas e sociais empregadas pelas estruturas de poder que legitimam a apropriação da produção. Parte-se das reflexões d'A origem da familia, da propriedade privada e do Estado, de Engels, articulando-as com obras que atualizam $\circ$ problema em análise: $\bigcirc$ nascimento da biopolítica, de Foucault, Circuito dos afetos, de Safatle e A nova razão do mundo, de Dardot e Laval. Examina-se o surgimento de uma classe social que, sem produzir, se apropria da produção e subjuga econômico e politicamente $\bigcirc$ produtor. Após, evidencia-se algumas decorrências da consolidação da divisão social de classes, como a tentativa de se "legalizar" a exploração econômica, naturalizando-a, e, principalmente, as práticas sociais (estatais, discursivas, morais e jurídicas) de subjetivação empregadas neste processo que resultam no surgimento do modelo neoliberal.

Este é um artigo publicado em acesso aberto (Open Access) sob a licença Creative Commons Attribution, que permite uso, distribuição e reprodução em qualquer meio, sem restrições desde que sem fins comerciais e que o trabalho original seja corretamente citado.
Palavras-chave: práticas jurídicas; subjetivação; apropriação; legitimação; neoliberalismo.

Abstract: This paper aims to analyze how global power structures' social and juridical practices employed by the capitalist model legitimize an appropriation of production. In this instance, this reaserch focus on The origin of the family, private property and the State, by Engels, articulating it with texts that actualizes the problem: The birth of biopolitics, by Foucault, Circuito dos Afetos, by Safatle, and The new way of the world, by Dardot and Laval. This research examines a social class that, without producing, appropriates the production and, as the same time, subdues the producer economically and politically. At the end, we present some of the consequences of the establishment, creation and legitimization of the division of social classes, as an attempt to "legalize" an economic exploitation of others, naturalizing a social body, and, mainly, as social practices (state,

1 Doutoranda em Filosofia Radical e Teoria Crítica do Direito e do Estado pela UFMG. Mestra em Teoria do Direito e Graduada em Direito pela Pontifícia Universidade Católica de Minas Gerais. Coordenadora do grupo de pesquisa Teoria Crítica do Direito da PUC Minas. Advogada. E-mail: barbara.nlima@hotmail.com

2 Doutor em Direito Político pela UFMG. Mestre em Filosofia Política pela UFMG. Graduado em Filosofia (FAJE) e em Direito (FDMC). Professor. E-mail: ricardo mom@hotmail.com 
discursive, moral and legal) of subjectivity employed in this process which results in the creation of neoliberalism.

Keywords: juridical practices; subjectivation; appropriation; legitimation; neoliberalism.

\section{Introdução}

Este artigo tem por objetivo analisar práticas e dispositivos de poder que legitimam a acumulação de riquezas nas mãos de poucos e a apropriação da produção por entidades não produtoras, práticas estas empregadas por estruturas globais de poder, tal como Estado e Mercado. Além disso, pretendese compreender, ainda que esquematicamente, quais consequências estas práticas e dispositivos podem trazer. Quando se fala em dispositivo, pensa-se na definição trazida por Deleuze em Qu'est-ce qu'un dispositive?, que define um dispositivo como uma espécie de novelo ou um conjunto multilinear complexo e composto por "linhas" de distintas naturezas, incapazes de delimitar sistemas como homogêneos por conta própria, seguindo diferentes direções e fazendo emergir processos desequilibrados, nos quais as linhas se aproximam e afastam umas das outras. As linhas estão quebradas e submetidas a variações de direção e derivação, e os objetos visíveis, as enunciações formuláveis, as forças em exercício, os sujeitos numa posição, são como vetores e tensores nessa englobante rede. As três grandes instâncias do saber, poder e subjetividade não possuem contornos definitivos, sendo espécies de cadeias de variáveis relacionadas entre si. Com isso, será examinado como determinados dispositivos se constituem para, após, compreender seu funcionamento na sociedade. ${ }^{1}$

Nesta investigação, primeiramente serão apresentadas as condições sociais e econômicas que fizeram emergir a estrutura do Estado e a partir das quais surgiu tanto a divisão da sociedade em classes quanto uma classe que, mesmo não produzindo, detém a produção. Este caminho será guiado, em parte, pela obra A origem da família, da propriedade privada e do Estado, de Engels, para quem a história deve ser analisada segundo $\circ$ materialismo histórico: a investigação do progresso da humanidade deve examinar como a produção e a reprodução da vida imediata são decisivos. Isso porque ao produzirem meios de existência (alimentação, habitação e instrumentos para tais fins) e do próprio homem (para sua continuação enquanto espécie), condicionam radicalmente a ordem social pelo grau de desenvolvimento do trabalho e da família. "Quanto menos desenvolvido é o trabalho, mais restrita é a quantidade de seus produtos $e$, por consequência, a riqueza da sociedade; com tanto maior força, se manifesta a influência dominante dos laços de parentesco sobre o regime social". ${ }^{2}$

Logo, analisar a família e o trabalho é essencial para se compreender a ideologia do progresso humano e os fatores que levaram ao surgimento de uma determinada ordem social, que, ainda que permeada de nuances e particularidades intercambiáveis, se mantém enquanto estrutura divisora e hierarquizadora de classes ao longo da história. Em seguida, serão analisados os efeitos concretos das práticas que o

\footnotetext{
1 DELEUZE, Qu'est-ce qu'un dispositive?.

2 ENGELS, A origem da família, da propriedade privada e do Estado, pp. 2-3.
} 
capitalismo opera, especialmente em sua forma neoliberal. Este ponto da investigação irá se embasar, principalmente, no curso $O$ nascimento da biopolítica, de Foucault, e nas obras Circuito dos afetos, de Safatle e A nova razão do mundo, de Dardot e Laval. É preciso ressaltar, contudo, que embora os autores acima sejam utilizados para a elaboração do presente texto, não há nenhuma tentativa de constituição de uma linearidade teórica que ofereça $\circ$ sentido de continuidade entre suas obras. Ao contrário, os pressupostos e proposições de autores como Engels e Foucault apresentam aspectos, não raro, divergentes. A despeito dessas incongruências, evidenciadas, por exemplo, pela contraposição entre o materialismo histórico-dialético e a genealogia foucaultiana, a opção de uso da obra de Engles se justifica pela sua função de base teórica para a apresentação das condições econômicas e sociais que proporcionam o surgimento tanto do Estado quanto do Mercado, estruturas essenciais à análise do neoliberalismo. Nesse sentido, o neoliberalismo, embora discrepante do liberalismo no que se refere aos discursos e práticas que constituem $\circ$ sujeito, comporta em si a divisão da sociedade em classes (embora a tente disfarçar sob a máxima individualista do "euempresarial"), razão pela qual a já citada obra de Engels se faz necessária enquanto pressuposto teórico para a primeira parte do texto. Da mesma forma, tal como aponta Benjamin ${ }^{3}$, Engels descobre, a partir dos trabalhos de Morgan ${ }^{4}$, a comunidade "primitiva" como realidade histórica indissociável da luta moderna por uma nova comunidade, ou seja, por uma comunidade sem classes, tema não apenas atual, mas também imprescindível ao se discutir possibilidades alternativas ao modelo neoliberal.

Uma vez que a ordem capitalista, sobretudo em sua formulação neoliberal, se instaura na sociedade, ela traz consigo práticas e dispositivos de subjetivação que operam de modo a consolidar sua formulação global não apenas de modo a reprimir os indivíduos para que eles produzam segundo as expectativas industriais, mas de modo que, enquanto sujeitos "livres" e "soberanos de si", tais indivíduos se enxerguem no sistema de produção, passando a ter um sentimento de realização no próprio ato da produção em um movimento que vincula diretamente a maneira com a qual $\circ$ sujeito é governado com a forma pela qual ele próprio se governa. ${ }^{5}$ Nesse contexto, $\circ$ sujeito neoliberal simultaneamente se constitui e é constituído enquanto animal competitivo por meio de uma nova lógica normativa derivada de práticas discursivas e institucionais que produzem a figura do homem-empresa. ${ }^{6}$ Logo, opera-se mais que uma amenização do estranhamento existente entre objeto produzido e sujeito produtor - que era presente nos modelos iniciais do processo do capital: emerge uma noção de quase identificação radical entre sujeito e produção.

\footnotetext{
3 LÓWY, Walter Benjamin, e-book.

${ }^{4}$ Lewis Henry Morgan foi um antropólogo americano cujos trabalhos acerca do materialismo cultural e estrutura social influenciaram fortemente as obras tanto de Marx quanto Engels. Cf. MORGAN, Ancient society.

5 DARDOT; LAVAL, A nova razão do mundo, pp. 332-333.

6 DARDOT; LAVAL, A nova razão do mundo, p. 322.
} 


\section{O surgimento da classe comerciante}

Uma vez que para Engels a história deve ser analisada segundo o materialismo, a investigação do "progresso" da humanidade, bem como do surgimento de estruturas como o Estado, deve levar em consideração a produção e a reprodução da vida imediata, que são fatores decisivos na história. Isso porque a ordem social é condicionada pela produção dos meios de existência (alimentação, habitação e instrumentos para tais fins) e do próprio homem enquanto espécie, razão pela qual o grau de desenvolvimento do trabalho e da família são centrais. "Quanto menos desenvolvido é o trabalho, mais restrita é a quantidade de seus produtos e, por consequência, a riqueza da sociedade; com tanto maior força, se manifesta a influência dominante dos laços de parentesco sobre o regime social", razão pela qual analisar $\circ$ grau de desenvolvimento destas categorias é necessário para se compreender a ordem social (presente ou passada). ${ }^{7}$

Em relação a obra de Engels, faz-se necessário destacar que, em que pese a importância do materialismo histórico para a análise das relações de produção e a consequente teorização e problematização da divisão social de classes, compreendemos a ideia de progresso histórico enquanto um modo particular de percepção do tempo que negligencia outras possibilidades de configurações sociais que não aquelas pautadas pela estrutura do Estado, relegando ao Outro um lugar de subalternidade ou, ainda, de barbárie. O conceito de progresso vincula-se perigosamente à classificação de desenvolvimento/subdesenvolvimento cujo "[...] biologismo da expressão não é senão a máscara furtiva da velha convicção ocidental, muitas vezes partilhada realmente pela etnologia, ou ao menos por muitos dos seus praticantes, de que a história tem um sentido único, de que as sociedades sem poder são a imagem daquilo que não somos mais e de que a nossa cultura é para elas a imagem do que é necessário ser. E não só o nosso sistema de poder é considerado $\circ$ melhor, mas chega-se mesmo a atribuir às sociedades arcaicas uma certeza análoga", conforme explica Clastres. ${ }^{8}$ Como efeito, a percepção do Estado enquanto destino de uma sociedade inferioriza, ainda que involuntariamente, outras configurações sociais sob o estigma da falta a partir de um patamar civilizatório eurocentrado.

Outra crítica acertada ao marxismo evolucionista de Engels é aquela proposta por Benjamin' que, a partir de suas intuições "antiprogressitas", se afasta das "ilusões do progresso" presente no trabalho da esquerda alemã. Benjamin, em sua desconstrução do discurso do progresso, parte do pressuposto de que a história é, na verdade, uma "forma heterodoxa do relato da emancipação", permitindo que seu trabalho se desenvolva enquanto uma crítica à modernidade industrial e capitalista a partir da análise das referências culturais e históricas précapitalistas, sem, no entanto, se aliar ao determinismo e ao tempo infinitamente vazio do progresso histórico.

Para Engels, Morgan descobriu o materialismo histórico na América provando que os sistemas de parentesco e as formas de família a eles

7 ENGELS, A origem da família, da propriedade privada e do Estado, pp. 2-3.

${ }^{8}$ CLASTRES, A sociedade contra o Estado, p. 32-33

9 LÓWY, Walter Benjamin, e-book. 
correspondentes foram decisivos na história. Já que o "progresso" humano acompanha o desenvolvimento dos meios de produção, Morgan classifica seus estágios em: selvagem - os homens se apropriavam diretamente dos produtos da natureza prontos para utilização, e a produção artificial simplesmente facilitava tal processo; barbárie aparece a criação de gado e a horticultura, iniciando o incremento da produção pela força de trabalho humana a partir da natureza; civilização - inicia-se com a fundição do ferro e a invenção da escrita alfabética, onde se complexifica a elaboração de produtos. Morgan debate o surgimento da família, da propriedade privada e do Estado:

De acordo com a concepção materialista, o fato decisivo na história é, em última instância, a produção e a reprodução da vida imediata. Mas essa produção e essa reprodução são de dois tipos: de um lado, a produção de meios de existência, de produtos alimentícios, habitação, e instrumentos necessários para tudo isso; de outro lado, a produção do homem mesmo, a continuação da espécie. A ordem social em que vivem os homens de determinada época ou determinado país está condicionada por essas duas espécies de produção: pelo grau de desenvolvimento do trabalho, de um lado, e da família, de outro. Quanto menos desenvolvido é o trabalho, mais restrita é a quantidade de seus produtos e, por consequência, a riqueza da sociedade; com tanto maior força, se manifesta a influência dominante dos laços de parentesco sobre o regime social. Contudo, no marco dessa estrutura da sociedade baseada nos laços de parentesco, a produtividade do trabalho aumenta sem cessar, e, com ela, desenvolvem se a propriedade privada e as trocas, as diferenças de riqueza, a possibilidade de empregar força de trabalho alheia, e com isso a base dos antagonismos de classe: os novos elementos sociais, que, no transcurso de gerações, procuram adaptar a velha estrutura da sociedade às novas condições, até que, por fim, a incompatibilidade entre estas e aquela leva a uma revolução completa. ${ }^{10}$
Os modelos de família correspondentes seriam: a família consanguínea, modelo familiar que exclui pais e filhos de relações sexuais recíprocas, onde os grupos conjugais se definem por gerações, isto é, irmãos são marido e mulher, de modo que a reprodução da família se dava por meio de relações mútuas e endógenas; família panaluana, modelo em que se exclui relações carnais entre irmãos, criando a categoria de sobrinhos e sobrinhas, primos e primas, aparecendo uma forma de matrimônio por grupos típico das comunidades comunistas, as gens, que se distinguem na mesma tribo; com a ampliação das proibições relativas a casamento, tornase cada vez mais impossível a união por grupos, que são substituídas pela família sindiásmica, em que há o matrimônio por pares, embora a poligamia e a infidelidade permaneçam direito do homem. Este modelo de família é o que permite o desenvolvimento da família monogâmica. ${ }^{11}$ No contexto em que reinava o matrimônio por grupos a tribo dividiu-se em grupos consanguíneos por linha materna, as gens, que são grupos de consanguíneos por linhagem e descendência que se unem por instituições sociais e religiosas e formam uma comunidade na qual é vedado o matrimônio. Os homens de uma linhagem buscam mulheres dentro da tribo, mas fora da sua gens. Já que os laços de parentesco eram determinados pela linha materna, pode-se dizer que houve um direito materno que precedeu o paterno.

Este artigo se detém no que se sucedeu à fase superior da "barbárie", e os índios americanos são tomados como exemplo da organização gentílica. A análise recai sobre os fatores que a fizeram sucumbir. Com a divisão da tribo em gens houve o

10 ENGELS, A origem da família, da propriedade privada e do Estado, p. 4.

11 ENGELS, A origem da família, da propriedade privada e do Estado. 
aumento populacional, e cada gens se divide. Mesmo com as divisões, as antigas gens permanecem, e a gens-mãe conservar-se como fratria, formando uma confederação de tribos aparentadas. Essa era uma organização simples, espontânea e adequada às condições sociais, apta a dirimir seus conflitos internos. Os externos eram definidos em guerras, podendo resultar na ruína da tribo, não em escravização. A ausência de escravidão era a altivez e a limitação desta época, pois não havendo divisão de classes, não se maximizava a produção pela exploração de mão de obra servil. A divisão em classes pressupõe uma divisão artificial do trabalho, ao passo que a repartição laboral deste período era "espontânea"12, a partir do gênero: o homem caça, pesca, busca matériaprima, produz instrumentos e guerreia; a mulher cuida da casa. As tribos eram rodeadas de uma região de caça e de bosques que as separavam, com uma população dispersa, densa só no local de residência. A economia era comunista pois tudo era comum. ${ }^{13}$

Em outros lugares (como na Ásia) surgiram práticas pastoris e de horticultura que deram a estas sociedades destaque em termos produtivos. A partir da domesticação de animais como a búfala, aumentou-se e periodizou-se a produção de víveres, lacticínios e carnes. A horticultura, possivelmente desconhecida dos asiáticos na fase inferior da barbárie, precedeu a agricultura. A terra era cultivada comunitariamente $e$, ainda que não se saiba quando os rebanhos passaram a ser patrimônio dos chefes familiares e não mais da tribo, a aparição deles e das riquezas revolucionou a família: se providenciar a alimentação e produzir instrumentos para tanto havia sido tarefa do homem, logo a domesticação e a criação também; e se os instrumentos necessários às tarefas do homem pertenciam a ele, o gado e a mercadoria proveniente da troca também. "Todo o excedente deixado agora pela produção pertencia ao homem; a mulher tinha participação no consumo, porém não na propriedade. $O$ pastor, com a riqueza, relega a mulher para o segundo plano". ${ }^{14}$ Ainda que a divisão familiar do trabalho continuasse igual, fora da família as relações foram reformuladas quando o trabalho doméstico se torna menos importante que $\circ$ produtivo (do homem).

Com o desenvolvimento de setores da produção (criação e cultivo) a força de trabalho se tornou apta a produzir cada vez mais, viabilizando a troca regular de produtos entre as tribos. O principal artigo oferecido pelas tribos pastoris às vizinhas era o gado, que adquiriu a função de moeda, sendo a mercadoria pela qual se avaliava as demais ${ }^{15}$. Surgindo formas de riquezas oriundas das trocas de produtos, aumentou-se a quantidade de trabalho diário dos membros da gens para elevar a produção e, com isso, a riqueza. Ainda assim, a necessidade de força de trabalho era crescente e foi resolvida

\footnotetext{
12 A despeito da perspectiva essencialista apresentada por Engels, compreendemos a ideia de gênero enquanto categoria discursiva e, portanto, como construto social cujas caracterizações se dão por meio de estruturas de diferenciação que inevitavelmente hierarquizam e oprimem. Nesse sentido, a atribuição natural da divisão do trabalho produtivo à categoria homem e do trabalho reprodutivo à categoria mulher acaba por reafirmar a ontologização de predicamentos decorrentes da sociedade patriarcal em que vivemos. Cf. BUTLER, Problemas de gênero.

13 ENGELS, A origem da família, da propriedade privada e do Estado.

14 ENGELS, A origem da familia, da propriedade privada e do Estado.

15 ENGELS, A origem da família, da propriedade privada e do Estado.
} 
pela guerra, que passou a escravizar prisioneiros para servir de mão de obra. Nesse processo ocorreu a primeira divisão de classes: senhor e escravo, explorador e explorado.

O que se seguiu disso foi o domínio do ferro que, somado a outras condições socioeconômicas, culminou na fase superior da "barbárie", momento em que os

[...] povos civilizados viveram sua época heróica; período da espada de ferro, mas também do arado e do machado de ferro. Ao por este metal a seu serviço, o homem se fez dono da última e mais importante das matérias-primas que tiveram, na história, um papel revolucionário [...]. O ferro tornou possível a agricultura em grande escala e a preparação, para o cultivo, de grandes áreas de florestas; deu aos artesãos um instrumento cuja dureza e cujo fio jamais havia podido ter pedra alguma ou qualquer metal. ${ }^{16}$

O rápido aumento da riqueza individual e o incremento da arte de tecer, do trabalho com metais e dos ofícios especializados, levou à variedade e ao crescimento da produção, acarretando na valorização ainda maior da força de trabalho. A escravidão, até então nascente e esporádica, se tornou socialmente indispensável. Houve também a divisão social do trabalho entre artesanato e agricultura, surgindo a produção mercantil (diretamente para a troca) e o comércio amplo, não só no interior e nas fronteiras das tribos, mas por mar. Ainda, os metais preciosos se tornaram a mercadoria universal (moeda) e o objetivo último do homem. Essa nova divisão do trabalho leva a outra divisão de classe: além do livre e o escravo, passou a haver a distinção entre o pobre e o rico. As consequências foram: 1) o fim do trabalho comum na terra e a distribuição do solo entre as famílias (primeiro por tempo determinado e depois permanentemente) devido à necessidade de acumulação individual de riqueza; 2) o aumento populacional devido à necessidade produtiva crescente, causando uma união interna e externa das tribos e a fusão de seus territórios; 3 ) a colocação da questão da segurança como algo de primeira ordem, pois se a riqueza individual passa a ser buscada irrestritamente, o acúmulo de uns leva à cobiça de outros; 4) a guerra passa a ser empreendida permanentemente visando o saque para a ampliação da riqueza, não mais para vingar uma agressão ou ampliar territórios. ${ }^{17}$

Visto que a acumulação de riquezas passa a ser o telos; as riquezas dos vizinhos viram alvo de cobiça; guerras regulares visam a rapina: muralhas são construídas ao redor das cidades e a nova arquitetura interna passa a ser definida por casas individuais de pedras ou tijolos. A segurança se torna extremamente relevante, pois o seu grau de efetividade proporciona um maior ou menor potencial de acúmulo de riquezas. Com isso, o chefe militar se torna um funcionário permanente e se cria uma assembleia e uma democracia militar egressa da antiga ordem gentílica. A organização das tribos para a regulamentação de seus assuntos vira um aparato de saque e opressão de vizinhos, que são potenciais ameaças à segurança e ao acúmulo de riquezas. Os órgãos deixam de ser instrumento da vontade do povo e se tornam independentes, dominadores e opressores. $^{18}$

Tudo isso só foi possível porque a cobiça dividiu os membros das gens em ricos e

\footnotetext{
16 ENGELS, A origem da família, da propriedade privada e do Estado, p. 183.

17 ENGELS, A origem da família, da propriedade privada e do Estado.

18 ENGELS, A origem da família, da propriedade privada e do Estado.
} 
pobres, de modo que as diferenças no seio da mesma gens se transformou em um antagonismo entre seus membros. As guerras de rapina aumentaram o poder do chefe militar, que passou a ser transmitido hereditariamente, constituindo-se os pressupostos da monarquia. A consolidação das divisões do trabalho e o aumento do contraste entre cidade e campo culminou na civilização. A sociedade antiga, que se baseava em uniões gentílicas, se reorganiza devido ao choque das classes sociais recém-formadas, dando lugar a uma sociedade organizada em Estado, cujas unidades inferiores já não são gentílicas e sim territoriais, ou seja, uma sociedade na qual o regime familiar está completamente submetido às relações de classe e luta de classes, sociedades estas que constituem o conteúdo de toda a história escrita até a atualidade.

Aqui ocorreu outra divisão do trabalho devido ao surgimento de uma classe que não se ocupa da produção, apenas da troca: os comerciantes. Se até então apenas a produção determinava a constituição e a divisão das classes (diretores/executores ou grandes/pequenos produtores), a classe comerciante não toma qualquer parte na produção, apenas conquista sua direção subjugando economicamente os produtores. Ela se coloca como o intermediador indispensável entre os produtores sob o pretexto de poupá-los da fadiga e do risco da troca, mostrando-se como um agente socialmente útil. Todavia, simplesmente explora os produtores ao exigir uma compensação desproporcional por seus serviços (na realidade insignificantes), levando à rápida concentração de riquezas e influência social em suas mãos, ocupando, "[...] no decurso desse período da civilização, posição de mais e mais destaque, logrando um domínio sempre maior sobre a produção, até gerar um produto próprio: as crises comerciais periódicas". ${ }^{19}$ Por meio do dinheirometal (mercadoria que encerra as demais), esse não produtor dominou a produção.

Ao lado da riqueza em dinheiro, mercadoria e escravos, aparece a riqueza em terra. A posse, antes coletiva, passa a ser hereditária (herança), surgindo a propriedade plena e privada do solo que permite sua alienação sem restrições, o que não existia na ordem gentílica. A propriedade suprema da gens é suprimida pela individual, rompendo o vínculo outrora indissolúvel entre proprietário e solo, que passa a ser mera mercadoria. A expansão do comércio e a progressão da propriedade territorial, do dinheiro e da usura levam à concentração da riqueza numa classe pouco numerosa, fenômeno acompanhado do empobrecimento das massas. Na Grécia por exemplo ocorreu um enorme aumento do número de escravos, pois trabalho forçado se tornou a base do edifício social. Assim, a sociedade antiga se reorganiza a partir do choque de classes, dando lugar ao Estado, cujas unidades inferiores já não são gentílicas, mas territoriais. Tal sociedade se define pela brutalidade do poder do dinheiro, que nenhuma legislação é capaz de submeter. Ele se constitui como uma potência que produz crises sistêmicas e as torna naturais ao corpo social.

\section{Práticas de legitimação da apropriação da produção}

Com o surgimento de uma ordem cujos antagonismos sociais não só são

\footnotetext{
19 ENGELS, A origem da família, da propriedade privada e do Estado, p. 187.
} 
irreconciliáveis, mas levados a limites extremos, consolida-se a divisão de classes sob o domínio do Estado, organização esta apta a "resolver" os conflitos entre os grupos antagônicos que a ordem gentílica não mais conseguia. Por mais que este regime tenha realizado mais coisas que o anterior, ele colocou em movimento os impulsos humanos mais vis em detrimento de suas melhores disposições: a vulgar ambição pela acumulação de riqueza individual como força motriz da produção. O modelo civilizatório ocidental, ao constituir como sua base a exploração de uma classe por outra, fez com que seu progresso fosse paradoxal: "Cada benefício para uns é necessariamente um prejuízo para outros; cada grau de emancipação conseguido por uma classe é um novo elemento de opressão para a outra". Se na barbárie não havia diferença entre direitos e deveres, na civilização há um contraste evidente, "[...] atribuindo-se a uma classe quase todos os direitos e à outra quase todos os deveres". 20

Não obstante retrocessos sejam evidentes, os exploradores se valem uma série de discursos que identificam, retoricamente, seus interesses com os da sociedade, como se o seu progresso equivalesse ao da sociedade. A classe dominante se vê obrigada a encobrir os seus males com um manto de caridade, elaborando uma "hipocrisia convencional" capaz, inclusive, de negar os seus males. Chega-se a sustentar que os opressores o fazem em benefício dos oprimidos e, "[...] se a classe oprimida não $\bigcirc$ reconhece, e até se rebela, isso, além do mais, revela sua mais negra (sic.) ingratidão para com seus benfeitores, os exploradores". ${ }^{21}$ Vários são os desdobramentos disso, dentre os quais as práticas de subjetivação oriundas da apropriação da noção de liberdade, sendo este o processo social, político e econômico que leva a colonização dos sujeitos mais longe e de forma mais efetiva, por criar uma aparente liberalização.

Com efeito, o neoliberalismo costuma ser pensado como uma simples doutrina econômica que, restringindo a intervenção do Estado nas relações econômicas do mercado, que devem se autogerir e regulamentar, leva ao equilíbrio social por meio do exercício da liberdade humana. Muitas vezes compreendida como uma simples continuação do liberalismo tradicional, essa doutrina adota uma espécie de "tese antropológica" ou "metafísica" no sentido de que o mercado e as relação econômicas "naturais" seriam capazes de equilibrar todos os processos sociais caso - Estado não interviesse nesta realidade auto evidente. Logo, por mais que o neoliberalismo seja conjecturado como mais uma escola, ele se torna muito mais do que isso, pois se arroga a posição de grade de inteligibilidade de todo o real para a atuação estatal e, até mesmo, dos agentes sociais (em um sentido moral, profissional, familiar, político), analisando apenas a efetividade das atuações ou abstenções estatais e humanas em maximizar a produção pelo e no mercado sob o estigma da competição, da absoluta individualidade e da auto responsabilização. Como será mais bem desenvolvido a seguir, uma determinada concepção de liberdade econômica se universaliza, atuando não apenas de modo repressivo, mas, sobretudo, através da produção de 
subjetividades, o que faz com que este processo seja bem mais efetivo. ${ }^{22}$

O liberalismo clássico se desenvolve a partir do século XVIII baseado no pressuposto de que a atuação e a intervenção do governo deveriam ser limitadas tanto no campo econômico como no que diz respeito às liberdades individuais. Sob esse ponto de vista, o governo liberal seria limitado por certas leis naturais que deveriam determinar as ações governamentais, sejam elas políticas ou econômicas. Por meio de técnicas utilitaristas, o governo liberal objetiva alinhar os interesses individuais ao bem geral segundo as doutrinas do direito natural e da dogmática do laissez-faire, tendo como principais expoentes teóricos autores como Adam Smith, no que se refere ao mercado, John Lock, em relação aos direitos e Jeremy Bentham, a respeito dos cálculos utilitarista. ${ }^{23} \bigcirc$ liberalismo tem como escopo apreender as leis "naturais" que regem o mercado, a lei da oferta e da demanda e, as relações humanas como um todo, visando equilibrar todo o aspecto social. Uma vez que os parâmetros limitadores propostos pelo liberalismo estabelecem a existência de uma lei naturalizada de mercado, tal lei não poderá ser atropelada pois, assim como quando a natureza é atropelada surgem consequências negativas imediatas, 0 mesmo ocorre com o mercado e sua natureza própria. Tais leis funcionam como manifestações da verdade, devendo ser respeitadas incondicionalmente. Ainda que essas leis naturais não sejam passíveis de ser inteiramente apreendidas, caso se tente alterá-las, acaba-se por desnaturalizálas. ${ }^{24}$

Esse discurso opera de modo a legitimar a apropriação e a acumulação de riquezas não tanto pelas suas demonstrações teóricas, mas justamente por tudo o ele se propõe a realizar (ou deixar de realizar) no âmbito das práticas sociais efetivas. Isso porque ao formular um ramo científico, com status absoluto e que gera efeitos de verdade para além de seu objeto, o liberalismo sustenta que eventuais apropriações da produção e acumulações de riquezas por uma parcela da população levam, caso não haja uma intervenção nos processos econômicos, a conquistas não somente dos ricos, mas de toda a sociedade. Ou seja, a liberdade econômica de agentes econômicos que detém as condições de possibilidade (o domínio sobre os meios de produção) para usufruir e impor sua "liberdade" legitimam sua condição de não produtor e, ainda, sustentam que se todos trabalharem para que eles alcancem os seus interesses particulares, todos irão alcançar um estado de eudaimonia econômica. Desse modo de se legitimar a apropriação da produção e acumulação de riquezas através da apropriação da noção econômica de

22 Embora exista uma corrente de interpretação da história que tenda a considerar noções potencialmente universalizantes (capitalismo, liberalismo econômico, relativismo) como "religiosas" tomando como exemplo o texto de Benjamin, Capitalismo como religião - Arendt, de forma bastante coerente, rechaça estes argumentos. Segundo a autora, não se pode tomar uma concepção partindo do pressuposto de que o que ela mesma afirma enquanto doutrina é uma mentira apara enganar aqueles que dela discordam. Ou seja, não se pode tomar o comunismo como religião se o próprio comunismo não se coloca neste local. Em suma, para a pensadora, tal empreitada não só pode levar a interpretações forçadas de concepções teóricas, como corre o risco de esvaziar a experiência religiosa, ao torna-la uma forma de ideologia (ARENDT, A dignidade da política). Com isso, parece ser mais acertado classificar tais doutrinas como metafísicas, uma vez que pressupõem a existência de uma dimensão que está para além da realidade visível, palpável e terrena, seja esta realidade o mercado, seja ela uma divindade.

23 DARDOT; LAVAL, A nova razão do mundo, p. 34.

24 FOUCAULT, O nascimento da biopolítica. 
liberdade e da elevação social por meio do enriquecimento dos "comerciantes" decorrem consequências, tais como a promessa não cumprida de equilíbrio social e os efeitos opressores disso.

Quanto à promessa de equilíbrio, vale ressaltar que após décadas de liberalismo econômico e a consolidação absoluta da classe expropriadora do trabalho (os comerciantes) por meio da integração global do mercado, ocorreu não o cumprimento da promessa, mas sua radical distorção. Segundo um estudo recente da OXFAM Internacional, a riqueza acumulada por $1 \%$ da população mundial equivale à riqueza detida pelos outros $99 \%$ das pessoas. Além disso, as 62 pessoas mais ricas do mundo (grupo que sequer chega a ser uma fração considerável) detém cerca de $50 \%$ de toda a riqueza. Ainda essa mesma entidade evidenciou que "Nos Estados Unidos o 1\% mais rico acumulou $95 \%$ do crescimento posterior à crise de 2009 , enquanto os $90 \%$ mais pobres se empobreceram ainda mais". ${ }^{25}$

No que diz respeito às condições opressoras e brutais, sobretudo aquelas levadas a cabo pelo Estado, muitos são os exemplos, tanto de práticas de poder quanto de fatos passados. Pode-se, sinteticamente, analisar o modo como todos os aparatos de Estado foram apropriados na América Latina em grande parte do século XX para viabilizar uma ordem social que buscaria tão-somente a maximização dos processos econômicos pelo aumento da produção. Ainda que esta, no âmbito do Estado Democrático, seja uma função estatal, o que ocorreu neste contexto foi uma total apropriação da máquina estatal visando a realização de interesses dos não produtores, que se apropriavam da riqueza e da produção. ${ }^{26}$

O liberalismo econômico, na medida em que adota como pressuposto um ideal acerca da realidade (que é o de que as leis e processos econômicos sejam deixados livres para a sociedade alcançar algo próximo ao que um grego chamaria de eudaimonia), carrega em sua formulação uma "tese antropológica", uma concepção essencialista do ser humano. Se as relações econômicas são relações entre os indivíduos numa instância universal denominada mercado que, por sua vez, possui leis próprias que devem ser captadas pelos economistas (que são os analistas das leis universais da liberdade) de forma objetiva, essas leis do mercado, por serem absolutas, devem necessariamente ter como pano de fundo - dogma de que os indivíduos se comportam da mesma forma, com o mesmo ânimo e de acordo com os mesmos padrões. ${ }^{2728}$

O neoliberalismo, por sua vez, não se apresenta enquanto uma mera continuidade do modelo liberal, sendo, em verdade, uma nova racionalidade governamental que faz do mercado tanto - princípio pelo qual o governo dos homens se rege quanto o princípio do governo de si, desenvolvendo a lógica liberal como lógica normativa generalizada que perpassa desde as estruturas do Estado até a mais particular subjetividade. ${ }^{29}$ Muito mais do que um conjunto de práticas políticas, de uma ideologia e de uma nova reconfiguração das relações entre

\footnotetext{
${ }^{25}$ MATOS, Filosofia radical e utopia, p. 111.

26 FOUCAULT, Ditos e escritos VIII.

27 PIZZORNO, Foucault et la conception libérale de l'individu, p. 236.

28 SAFATLE, Circuito dos afetos, pp. 193-200.

29 DARDOT; LAVAL, A nova razão do mundo, p. 68.
} 
economia e Estado, o neoliberalismo é uma racionalidade governamental que modifica todos os aspectos domínio humano de acordo com uma perspectiva bastante específica da economia, fazendo com que toda ação se transforme em conduta necessariamente econômica, ainda que não diretamente monetizadas $^{30} \bigcirc$ neoliberalismo surge, conforme sugere Foucault, a partir de duas escolas diferentes: a ordoliberal (ou Escola de Freiburg), uma reação ao nazismo e ao fascismo cuja ênfase se encontrava na propagação da racionalidade formal do mercado, e a Escola de Chicago, cujo foco foi a expansão dos mecanismos neoliberais concretos, sendo a principal distinção entre o liberalismo e o neoliberalismo a generalização do modelo econômico para além das fronteiras do mercado, em um movimento de colonização do corpo social por princípios empresariais, que se tornam uma nova arte de governar. ${ }^{31}$

A necessidade de maximização da produção ressurge no contexto do neoliberalismo, quando não se podia mais sustentar sua coesão e adesão psicológica pelo recurso à ética do trabalho. De modo a atender a tal necessidade, o neoliberalismo foi muito além de um "[...] simples conjunto de condições para a internalização de dinâmicas repressivas capazes de determinar sujeitos em individualidades rígidas e funcionalizadas, como vemos nas 'sanções psicológicas' da moralidade própria ao espírito protestante do capitalismo", 32 formulando-se num modelo generalizável e introjetável: o dispositivo disciplinar do "ideal empresarial de si". Isso significa que os discursos liberais que a partir do século XVIII determinavam que o homem é o que ele realiza, colocando-o em uma posição de animal simultaneamente produtivo e consumidor, já não são mais os mesmos que, no século $X X$, passam a engendrar a figura do "sujeito empresarial", cuja centralidade se localiza no ideal da competitividade. ${ }^{33} \mathrm{Se}$ a antiga uniformização disciplinar causava um conflito entre a necessidade produtiva exigida e $\circ$ desejo recalcado, expressando tal sofrimento psíquico em neuroses, regimes de gestão neoliberais realmente eficazes não permitem tais clivagens, pois expropriam todas as motivações que poderiam propiciar experiências que não pudessem ser lidas pela lógica produtiva. Tal expropriação foi possível pela socialização da lógica econômica de modo que as pulsões não passassem pelas clivagens sob a forma do recalque. Com a lógica empresarial de si, todos os afetos do sujeito são colonizados e voltados à necessidade de produção, pois o se dá gozo no processo produtivo em si.

A absolutização do "livre mercado", além de ter levado a desigualdades substanciais, coloca problemas como pensar o homem estritamente como um ser individual de "mão-de-obra", por meio de práticas de subjetivação que levam à perpetuação desse modelo expropriatório. A frase "Economics are the method. The object is to change the heart and soul", dita por Margaret Thatcher, apresenta de forma bastante clara a profundidade do neoliberalismo no horizonte moderno. ${ }^{34}$

\footnotetext{
30 BROWN, Undoing the demos, p. 31.

31 BROWN, Undoing the demos, p. 59-61.

32 SAFATLE, Circuito dos afetos, p. 197.

33 DARDOT; LAVAL, A nova razão do mundo, p. 322.

34 SAFATLE, Circuito dos afetos, p. 196.
} 
Este novo modelo de acumulação para a extração absoluta da mais-valia pela internalização do "ideal empresarial de si" intensificou o desempenho no ritmo exigido pelas relações liberais hegemônicas ao operar a transformação da produção em gozo. Foi fundamental ao neoliberalismo a extensão dos valores de mercado à política, fazendo com que a forma-empresa fosse generalizada no corpo social de modo que até os próprios indivíduos passassem a se compreender como empresas. Isso significa que, muito além de inserir os valores do mercado no conteúdo da democracia, o neoliberalismo subverte as práticas, os princípios, a cultura, os sujeitos e as instituições da democracia compreendida como governo no povo, transformando-os em elementos econômicos que devem se comportar a fim de maximizar seu status competitivo e seu valor futuro. Consequentemente, indivíduos e Estados se tornam projetos de portfólio e gerenciamento orientados pela perspectiva de investimento dentro de um projeto econômico que substitui o ethos político. ${ }^{35}$ Os sujeitos passam a se definir e explicar "racionalmente" pela da lógica de mercado, compreendendo tudo aquilo que os afeta como um trabalho sobre si visando sua otimização produtiva, tornando possível a racionalização empresarial do desejo, fundamento para a internalização do controle baseado na autoavaliação constante por critérios empresariais. ${ }^{36}$

A "psicologização" das relações de trabalho, fundamental à generalização do ideal empresarial de si, criou uma zona intermediária entre as técnicas de gestão e os regimes de intervenção terapêutica, levando a uma mobilização afetiva dos meios de produção, acarreando a fusão dos repertórios de mercado com a linguagem do eu. Recursos psicológicos de uma "engenharia motivacional" (cooperação, comunicação, reconhecimento) se tornaram dispositivos de otimização produtiva. Além disso, tal processo é impulsionado pelo medo, pois, enquanto instância psíquica de auto-observação, faz com que 0 temor de não pertencimento ao conjunto humano devido ao fracasso como sujeito produtivo inviabilize a resistência à constituição psíquica. Ou seja, àqueles que possam resistir, há a circulação incessante do risco da "morte social", pois aos Estados e indivíduos que não se submetem ao processo de transformação empresarial resta a ameaça de falência, crise fiscal, crédito negado, queda na avaliação e, até mesmo, perda de legitimidade. ${ }^{37}$ Ainda, esse afeto se funda em formas de medo que se reproduzem no interior da sociedade, como a incessante insegurança de um estado constante de guerra interna, como se não houvesse distinção entre guerra e paz. ${ }^{38}$

No neoliberalismo os sujeitos racionais são aqueles capazes de organizar suas ações avaliando tanto sua produção, manutenção de seus bens e fruição de prazeres privados quanto a ampliação disso. São racionais pois colocam todo o seu mundo a serviço da utilidade produtiva. O trabalho, mais que algo expropriável, é um processo de reconhecimento e constituição de subjetividades racionais. Para além da compreensão do trabalho como alienação, a constituição neoliberal elimina as formas de estranhamento

\footnotetext{
35 BROWN, Undoing the demos.

36 SAFATLE, Circuito dos afetos.

37 BROWN, Undoing the demos.

38 SAFATLE, Circuito dos afetos.
} 
entre o sujeito produtivo e o objeto produzido, fazendo com que o sujeito se realize naquilo que produz, de modo que - trabalho se torna um dispositivo o moral que alcança a aparência de autogoverno, pois por meio dele se aprende a impor leis à vontade que serão reconhecidas pelo próprio sujeito como sua expressão, aprendendo a relativizar exigências imediatas de autossatisfação. Dessa forma, aqueles que são capazes de trabalhar são vistos como autônomos, material e moralmente, pois são aptos a impor uma lei a si mesmos que expressa "sua" própria vontade. Ainda que a relação entre trabalho e autoimposição de uma lei à vontade na formação moral produtiva já fosse explorada liberalismo, a reformulação faz do trabalho não um abrir mão do gozo imediato para usufruir dos bens materiais posteriormente, mas uma forma de gozo decorrente da aparente liberdade de produzir como obrigação social. ${ }^{39}$

\section{Conforme Matos:}

Toda a discussão sobre o sistema políticojurídico-econômico atual levada a cabo dentro desse sistema e mediante seus próprios instrumentos é não apenas inútil, mas perigosa. Em especial, as supostas reformas e melhorias que o capitalismo proporcionaria no contexto do trabalho não são mais do que novas formas de dominação. Um exemplo extremo se relaciona à reivindicação de mais tempo livre e horas de descanso para os trabalhadores, o que vinha antes da crise de 2008, inclusive com a efetiva adoção de políticas de diminuição das horas diárias e semanais de labor. Mas para que servem essas horas livres? $\mathrm{Em}$ uma sociedade dominada pelo espetáculo e pela especulação, a que se entregarão os trabalhadores em seus momentos de folga, senão à contínua autopromoção dessa mesma sociedade? Mais horas livres significa mais servidão [...]. ${ }^{40}$
A própria liberdade política poderia ser colocada como uma decorrência da liberdade econômica, ou seja, se esta for assegurada, necessariamente aquela será alcançada. Sendo o capitalismo competitivo a organização econômica que viabiliza a liberdade econômica, isso significa que ela produz, necessariamente, a liberdade política, na medida em que tal modelo seria capaz de separar (não apenas em abstrato, mas no real) 0 poder econômico do poder político. Nos termos de Friedman, existem fortes evidências históricas que demonstram que a relação entre liberdade política e livre mercado. Uma vez que o Ocidente vive em um estado de liberdade, as pessoas tendem a esquecer $\circ$ quão limitado seria $\circ$ espaço de tempo e a parte do mundo onde há liberdade política, sendo a tirania, a servidão e a miséria o estado típico da humanidade. A liberdade política só emerge na contemporaneidade (assim como emergiu na era clássica e em Roma) e efetiva a potencialidade liberal humana com o mercado livre e o desenvolvimento das instituições capitalistas.

Foucault expõe que é como se o ser humano fosse marcado por natureza por uma essência de liberdade econômica, o que é o elemento que deixa patente que - neoliberalismo vai muito além de uma mera doutrina ou corrente econômica. É como se a "natureza" tivesse querido que o ser humano "[...] fosse entregue à atividade econômica que é a da produção e da troca. [...] a natureza de certa forma lhe ditou por baixo do pano, de certa forma deixou impressas nas disposições das coisas, da geografia, do clima, etc". ${ }^{41}$

\footnotetext{
39 SAFATLE, Circuito dos afetos.

40 MATOS, Filosofia radical e utopia, p. 115.

${ }^{41}$ FOUCAULT, O nascimento da biopolítica, pp.78-80.
} 


\section{Considerações finais: o \\ "avesso" das democracias modernas}

Morais e Silva ${ }^{42}$ analisam, a partir das reflexões foucaultianas sobre as ditas "democracias liberais", aqui compreendidas em seu sentido político e não enquanto modelo econômico, algumas das implicações e paradoxos que se instauram a partir da naturalização das práticas legitimadoras de um modelo neoliberal, sendo a principal delas limitações radicais a qualquer tipo de liberdade que não seja a econômica. Com efeito, explicam os autores que o liberalismo político, para que se legitime, cria elementos que vão muito além de uma simples ideologia econômica. Também como este texto tentou evidenciar, $\circ$ neoliberalismo acaba por se constituir como uma forma de metafísica, que coloniza subjetividades para que consiga tornar 0 modelo de espoliação (descrito e detalhado por Engels) não só aceitável, mas como o único modelo defensável possível. Por conseguinte, o neoliberalismo se transforma em um ente produtor de exercícios de poder que não apenas restringe, mas que produz subjetividades, fomenta uma razão de estado moderna baseada em uma artificialidade soberana laica que transfere a onipresença do Deus medieval para os pressupostos liberais e teorias soberanas.

Necessário frisar que mesmo que noções e dispositivos como o "Estado Social" tenham se interposto em meio às discussões levantadas, ainda assim a preocupação estaria centrada na questão de uma essência privada e econômica do ser humano. A função de um governo preocupado com $\circ$ bemestar social seria a de proporcionar aos seus cidadãos condições de possibilidade para que eles pudessem ser livres em termos substanciais, e não apenas em termos formais. Assim, proporcionar certos tipos de "assistência" pela via estatal não seria, propriamente, uma mudança de paradigma em relação à forma como o ser humano é compreendido "metafisicamente", mas de tentar atenuar alguns dos problemas que esta metafísica econômica impõe. Neste sentido, $\circ$ objetivo das intervenções estatais na "ordem econômica" ou a "constitucionalização" de uma "ordem social", mesmo que tenham sido conquistas importantes, podem ser situadas como uma forma de intervenção visando não intervir mais, ou seja, intervir visando, tão somente, proporcionar mais liberdade a todos. Logo, o neoliberalismo enquanto concepção metafísica se fez presente mesmo nas metamorfoses que $\circ$ Estado de Direito sofreu. ${ }^{43}$

Justamente por não ser o objetivo do neoliberalismo uma limitação das ações de governo de modo a promover a liberdade e a essência humana, mas um governar mais profundo e coeso das sociedades modernas, Opitz e Kramann analisam a questão do governo "liberal" pelas práticas locais de segurança, expondo que o neoliberalismo, longe de propiciar mais liberdade, a subverte. As análises apresentadas pelos autores se dão no sentido de evidenciar as formas liberais de governo que, ao contrário do que se poderia colocar, restringem a liberdade sob o argumento de aumentála, legitimando-se por meio de um discurso que defende a natureza liberal

42 MORAIS SILVA, O liberalismo econômico e as práticas de segurança, pp. 221-242.

43 MORAIS, SILVA, O liberalismo econômico e as práticas de segurança, p. 221-242. 
do homem. Para Opitz ${ }^{44}$, o Estado Liberal, e o neoliberal, assume o mesmo papel das teorias soberanas de outrora, sendo uma doutrina que, buscando se colocar como uma metafísica, intenta legitimar certas práticas de governo que, mesmo em total desacordo com o princípio norteador das instituições democráticas liberais (a liberdade), estão paradoxalmente a serviço delas. ${ }^{45}$

Em um espaço de governo liberal em que os princípios universais ditam que os indivíduos devem exercer sua liberdade frente ao Estado, que deve respeitá-la, emergem uma série de discursos que chamam a atenção para uma necessidade premente de segurança para que os indivíduos possam exercer a sua liberdade, uma vez que sem segurança, a essência humana não poderia encontrar um espaço para se manifestar plenamente. Opitz e Krasmann ${ }^{46}$ citam vários exemplos: em 2006 foi colocada em discussão uma proposta legislativa na Alemanha, permitindo à força aérea abater aeronaves com civis a bordo, desde que houvesse ameaça terrorista; o diretor do Escritório Federal Alemão para Proteção da Constituição, Heinz Fromm, declarou que informações advindas de fontes exteriores, mesmo extraídas mediante tortura, devem ser utilizadas; prisões americanas que encarceram e torturam sujeitos que ameaçam a segurança nacional. Emerge, em meio a este modelo de "democracia liberal", todo um aparado jurídico que é ajustado em torno do conjunto de práticas disciplinares, direcionado principalmente pela classe dominante e democraticamente representada (a burguesia). Assim, "Para que certo liberalismo burguês tenha sido possível no nível das instituições, foi preciso, no nível do que chamo os micropoderes, um investimento muito denso nos indivíduos, foi preciso organizar a grade dos corpos e dos comportamentos. A disciplina é o avesso da democracia". ${ }^{47}$ Por essa razão, Foucault conclui que, quanto mais democracia há, mais disciplina há.

Assim, o poder disciplinar se articula com as formas legais abstratas de uma forma tão refinada que, por mais que elas tenham um modo de operar aparentemente conflitante (pois uma produz corpos dóceis e a outra reprime), essas realidades coexistem sem se anularem, pois atuam em âmbitos diferentes: a teoria jurídica legalista atua em níveis formais, de modo a conferir legitimidade às práticas punitivas "humanistas", ao passo que o poder disciplinar, ao impor vigilância perpétua, sanções normalizadoras e saberes acerca do corpo, impõe práticas nada humanistas, legitimadas pela soberania igualitária. Assim, as modalidades de exercício de poder se complementam e, ainda que exerçam práticas de poder aparentemente opostas, são capazes de coexistir sem conflitarem. Este é uma das faces do ideal empresarial de si como modelo de subjetividade que não apenas reprime, mas produz subjetividades no modelo liberal, acoplando ao seu modo de funcionamento uma série de dispositivos que, por sua vez, tornarão viáveis o emprego de práticas neoliberais.

Discursos de segurança apontam para uma ilimitação e multiplicação das tecnologias de governo populacional, acarretando, com isso, uma erosão de

\footnotetext{
44 OPITZ, Govern unlimited.

45 MORAIS, SILVA, O liberalismo econômico e as práticas de segurança, p. 221-242.

46 OPITZ, Govern unlimited, p. 96.

47 FOUCAULT, Ditos e escritos VIII, pp. 38-39.
} 
distinções como legal/ilegal, privado/público, civil/militar. Assim, em nome da proteção da liberdade (atributo universal), inúmeras práticas locais que a contradizem são empregadas. Logo, por mais que a democracia liberal seja afetada por um profundo paradoxo, como uma prática de governo que limita e possibilita o governo, a tese de Foucault é a de que o neoliberalismo é uma prática refletida de governo que, como tal, governa a população e não possibilita um espaço de não intervenção aos indivíduos em que eles possam se realizar enquanto seres dignos e absolutamente iguais ${ }^{48} 49$. $\mathrm{Em}$ outras palavras, práticas de segurança de governos liberais são o avesso da democracia, pois, ainda que seus mecanismos sejam capazes de coexistir com os ideais modernos democráticos (pois atuam em instâncias distintas), direitos e liberdades fundamentais e individuais são deturpados, visto que operam mecanismos contrários ao direito igualitário 50 .

Assim, se as práticas de segurança intervêm, justificando-se no interesse de possibilitar a liberdade, a governamentalidade responderá a questões como: quais práticas de liberdade são desejáveis? Quais são as consequências negativas possíveis? Há medidas interventivas viáveis? Quais são as fontes de perigo em potencial? Em que forma e até que ponto o perigo pode ser tolerado? Como ele pode ser neutralizado? Vale a pena o custo da neutralização? $\mathrm{Na}$ medida em que os dispositivos de segurança são aliáveis à expansão de modos iliberais de governo, a segurança, em última instância, inverte-se dentro da máquina soberana.

\section{Referências}

ADVERSE, Helton. Liberdade e governamentalidade: Foucault e a genealogia do liberalismo. Revista Estudos Filosóficos, $\mathrm{n}^{\circ} 12,2014$. Disponível em http://www.ufsj.edu.br/portal2repositorio/File/revistaestudosfilosoficos /art2\%20rev1 2.pdf. Acesso em 10 de agosto de 2014.

ARENDT, Hannah. A dignidade da política. Trad. Helena Martins, Frida Coelho, Antonio Abranches, César Almeida, Claudia Drucker e Fernando Rodrigues. Organização, introdução e revisão técnica de Antonio Abranches. Rio de Janeiro: Editora Relume Dumará, 2002.

BRÖCKLING, Ulrich, KRASMANN, Susanne, LEMKE, Thomas. Governmentality: current issues and future challenges. Nova lorque: Routledge, 2011.

BROWN, Wendy, Undoing the demos: neoliberalism's stealth revolution. New York: Zone Books, 2017.

CLASTRES, Pierre. A sociedade contra o estado. Trad. Theo Santiago. São Paulo: Ubu, 2017.

DARDOT, Pierre; LAVAL, Christian. A nova razão do mundo: ensaio sobre a sociedade neoliberal. Trad. Mariana Echalar. São Paulo: Boitempo, 2016.

DELEUZE, Gilles. Qu'est-ce qu'un dispositive? In: Michel Foucault philosophe: Rencontre Internationale,

\footnotetext{
48 ADVERSE, Liberdade e Governamentalidade.

49 PIZZORNO, Foucault et la conception libérale de l'individu.

50 MONOD, Foucault.
} 
Paris 9, 10, II janvier 1988. Sevil/Gallimard, 1989.

ENGELS, Friedrich. A origem da familia, da propriedade privada e do estado. Trad. Leandro Konder. Rio de Janeiro: Editora Civilização Brasileira, 1984.

ENGELS, Friedrich. Ludwig Feuerbach e o fim da filosofia clássica alemã. Trad. José Barata-Moura. In: ENGELS, Friedrich. Obras escolhidas. Moscou, 1982.

FOUCAULT, Michel. Ditos e escritos VIII: Michel Foucault, segurança, penalidade e prisão. Org. Manoel Barros da Motta. Rio de Janeiro: Forense Universitária, 2012.

FOUCAULT, Michel. Em defesa da sociedade. Trad. Maria Ermantina Galvão. São Paulo: Martins Fontes, 1999.

FOUCAULT, Michel. O nascimento da biopolítica. Trad. Eduardo Brandão. São Paulo: Martins Fontes, 2008.

FOUCAULT, Michel. Segurança, território e população. Trad. Eduardo Brandão. São Paulo: Martins Fontes, 2008b.

LOWY, Michael. Walter Benjamin: aviso de incêndio - uma leitura das teses "Sobre o conceito de história". Trad. Wanda Nogueira Caldeira Brant, Jeanne Marie Gagnebon e Marcos Lutz Muller. São Paulo: Boitempo, 2005.

MATOS, Andityas Soares de Moura Costa. Filosofia radical e utopia: inapropriabilidade, an-arquia, a-nomia. Rio de Janeiro: Via Verita, 2014.

MONOD, Jean-Claude. Foucault: la police des conduites. Paris: Éditions Muchalon, 1997.

MORAIS, Ricardo Manoel de Oliveira. Normalização e processos de constituição da verdade. Revista de Estudos Constitucionais, Hermenêutica e Teoria do Direito (RECHTD), volume 7, número 2, pp. 197-209, 2015. Disponível em https://www.academia.edu/30734895 /Normalização_e_processos_de_constit vição_da_verdade_Normalization_and _processes_of_truth_constitution. Acesso em: 30 jun. 2017.

MORAIS, Ricardo Manoel Oliveira; SILVA, Adriana Campos. O liberalismo econômico e as práticas de segurança: o "avesso" das democracias liberais. Revista da Faculdade de Direito UFPR, Curitiba, PR, Brasil, v. 62, n. 3, pp. 221 242, set./dez. 2017. Disponível em: http://revistas.ufpr.br/direito/article/vi ew/53720. Acesso em: 21 mai. 2020.

MORGAN, Lewis H. Ancient society. Chicago: Charles H. Kerr \& Company, 1990.

OPITZ, Sven. Govern unlimited: the security dispositif of iliberal governmentality. In: BRÖCKLING, Ulrich, KRASMANN, Susanne, LEMKE, Thomas. Governmentality: current issues and future challenges. Nova lorque: Routledge, 2011.

PIZZORNO, Alessandro. Foucault et la conception libérale de l'individu. In: Michel Foucault philosophe: Rencontre internationale, Paris 9, 10, II janvier 1988. Sevil/Gallimard, 1989.

SAFATLE, Vladimir. Circuito dos afetos. São Paulo: Cosac Naify, 2015.

Recebido em: 31.10 .2020

Aprovado em: 05.1 1.2020 